\title{
Descriptive Analysis of the Relationship between Supply Chain Management and Business Performance: Evidence from Mali.
}

\author{
Kone Abdrahamane Salia Sinaly Traore Aly Yorote \\ Université des Sciences Sociales et Gestion Bamako Mali
}

\begin{abstract}
Through this study, we seek to evaluate the impact of supply chain management on the performance of a few companies in Mali empirically. We favored an approach that links four SCM practices across a variety of dimensions of performance. In our methodology, we used the process of performing a descriptive analysis of the data. At the end of this study, it should be remembered that the practices of the management of the supplier relationship and the exchange and sharing of information constitute the two most productive practices of the Supply Chain Management for the companies of our sample. Also, among the dimensions of the performance considered, financial performance and customer satisfaction are the two most sensitive variants of SCM practices. Keywords: Performance, Supply Chain Management, information, Customer.
\end{abstract}

DOI: $10.7176 / \mathrm{EJBM} / 11-15-19$

Publication date:May $31^{\text {st }} 2019$

\section{Introduction}

More specifically, our work focuses on the impact of SCM on business performance. To do this, we consider four types of MSC practices on the one hand and two aspects of performance on the other. The four practices that will hold our attention are the management of the supplier relationship, the exchange, and sharing of information, the quality of the shared information as well as the management of the customer relationship. In terms of performance, we will focus on both financial and non-financial performance. The goal here is to answer the question: what is the impact of SCM practices on business performance?

This study is thus of particular interest for Malian companies. It identifies the main SCM practices adopted in this sector and those that will improve performance. The present work is articulated as follows. The first section describes the methodological approach used to conduct the survey. In order to perform a rigorous analysis of the empirical relationship between SCM practices and business performance, we adopt a descriptive approach. Data analysis is done using Excel

\section{Literature Review}

The performance reflects how an organization reaches its objectives set on the market like its financial objectives (Yamin and al., 1999; Li and al., 2006). In the short run, the objectives of SCM are mainly to increase productivity and to reduce stocks and the time of the operating cycle of the organization. Whereas in the long run, it has as objectives to increase the market shares and the benefit of the various members of the chain of value (Tan and al., 1998). Beyond the general standard centered on the attack of the objectives (Bourguignon, 1995), it is essential to define concrete and actionable indicators to guide the leaders in their choices.

Since the decades, financial indicators such as the profitability of the investment (Return on Investment or KING), the profitability of the credits (Return On Assets or ROA), the profitability of capital clean (Return On Equity or $\mathrm{ROE}$ ), the profit margin on the sales (Return On Sales or ROS), played a leading role in the techniques of performance evaluation of an organization in general (Kaplan and Johnson, 1987; Vickery and al., 1999; Stock and al., 2000; Zhang, 2001; Cauvin and Bescos, 2005; Li and al., 2006; Brulhart and Moncef, 2010), and of SCM in particular (Wisner, 2003; Li and al., 2006; Koh and al., 2007; Green and al., 2007; Chow and al., 2008, etc). These measurements are often supplemented by the classical indicators resulting from the management audit: profit, requirement in working capital, growth of the sales and treasury (Lusch and Brown, 1996; Siguaw and al., 1998; Tan and al., 1998; Moncef, 2008; Brulhartet Moncef, 2010, etc).

However, to appreciate the performance only through indicators of financial nature involves a risk in the sense that, the value of the company is made up of tangible and intangible elements. Therefore, if the financial indicators take into account the real elements of the value of the company, they cannot measure the part of the intangible elements. This limit, in the beginning, brings many criticisms relating to the incapacity of the financial indicators to apprehend the total performance of the company. For most authors (for example, Ittner and Larcker, 1998; Kaplan and Norton, 1992; Kaplan and Norton, 2001; Ittner and al., 2003; St-Pierre and al., 2005; Gumb, 2005), these indicators do not make it possible to take into account the investment of the intangible credits such as the satisfaction of the customer or the innovation. As such, the financial indicators only give one partial vision of the 
performance, primarily in the short run. However, every undertaken knows that if the customers gradually become sulky in their offers (because their preferences change, because a concurrent offer is gravitational, etc), the longterm financial results would be threatened. This is why, the companies often privilege the relations with the customers and consequently direct their strategies towards the satisfaction of the latter via an excellence in the delivery in time and in quality (Ellram and Cooper, 1990; Cooper and al., 1997a; Lambert and al., 1999; Mentzer et al., 2001; Morana J., 2009). It is thus essential, and even impossible, not to take into account this dimension as far as the total performance of the company. Gets a move on, L. (2011) ${ }^{1}$ specifies within this framework" that a strictly economic vision of the performance leaves side the dependent stakes with staff, his competences, and its motivation. However, the results are not only done all. To know where one is in terms of human resources is a true managerial need ".To deal with these dimensions and to make at the same time, the limits related to the financial indicators. Many theoretical developments were presented during these last years, bearing on the installation of instrument panels (Kaplan and Norton, 1992.1996 and 2001; Mendoza and Zrihen, 1999; Germain, 2005), with like objectives enriching and not supplementing financial measurements through indicators - financial (Said and al., 2003 and St-Pierre, 2005).

In the case of the management of logistics ${ }^{2}$, reliability results in the capacity to deliver in a correct way the excellent product, in the right place, at the appropriate time, under the conditions of required packing, in quantity, documentation and with the excellent customer. The reactivity is, as for it, the capacity to adapt volumes of production and the variety of the products to the fluctuations of the request, like accelerating the marketing of a new product. From agility, it is the flexibility of the processes, the resources, the organizations, and the supply chains, which is searched to cope with unstable, turbulent, dubious and risked environments, and taking benefit from the market opportunities.

Lastly, the fourth criterion is related to the satisfaction of the employees (Kaplan and Norton, 1992), and the environmental concern. It returns to the social and societal performance of the company (Brulhart and Moncef, 2010).

However, as well for the financial indicators as for those non- financial, it is of habit to regard them as complementary elements like substitutes. Indeed, despite criticisms whom they are the subject, the financial indicators have a certain number of advantages: they are easily measurable, comparable and reliable (Barabel, 1999; Ittner and al., 2003). Despite significance attached to the non- financial indicators, the idea of a combination of these two facets (financial indicators and non - financial) seems more relevant to have a widened vision of the performance.

Within the framework of this study, summons us not to be favorable to the combination of the financial indicators and non- financial. According to Brulhart and Moncef work (2010), we refer to Balanced Scorecard of Kaplan and Norton (1992, 1998 and 2001) steady to the performance evaluation generated by the practices of SCM (Bhagwat and Sharma, 2007).

\section{Methodology 3.1 Study population}

Goldfarb and Pardoux (2011) define a population as the set of elements to which the studied data relate. In this work, the population is composed of all the enterprises of the cotton sector of Mali. To warrant the robustness of our results, we selected companies randomly. For this purpose, we based ourselves on the list of 50 cotton companies provided by the national statistical institute.

\subsection{Data collection procedure}

The approach used to conduct this study is essentially quantitative. In this framework, we used a structured questionnaire in which the questions asked are direct and closed, in order to better guide the research and facilitate the coding of the answers.

\footnotetext{
${ }^{1}$ MagneLourent: Performance, piloting andstrategy: around work of Kaplan and Norton,published by Wise the 12/9/2011. Lin k:https://blog.sage.fr/performance-pilotage-et-strategie-autour-des-travaux-de-kaplan-et-norton/

2 Supply Chain meter site:http://www.supplychainmeter.com/SUPPLYCHAINMETER_WEB/FR/La_performance_logistiq ue leviers_logistiques.awp
} 
It should be noted any time that a pilot study has been carried out beforehand to test the questionnaire with fifteen (15) randomly selected companies. This exercise allowed us to revise and improve the questionnaire.

For each company surveyed, we sent the questionnaire to the Supply Chain Manager, the Financial Manager, and the Director-General. We then examined the relevance of the answers provided by the respondents before extracting the database.

\section{Descriptive analysis and data discussions}

This section is devoted to the descriptive analysis of the data. The goal is to conduct an exploratory analysis to highlight early trends and identify practices that have a potential impact on business performance. The presentation of the results of this section is in the form of tables and graphs.

\subsection{The response rate}

Of the 50 companies targeted for our study, 31 finally answered the questionnaire, a response rate of $62 \%$. This response rate is representative of the target population. Indeed, it is above $50 \%$, which is often considered an acceptable threshold in the social sciences (Richardson 2005, Mugenda and Mugenda 2003).

\subsection{Relationship between SCM practices and business performance}

This part of the work seeks to analyze the relationship between SCM and business performance. To this end, companies were asked to give their perceptions of the impact of SCM practices on their performance level.

To facilitate descriptive analysis, we have excluded the practice of the quality of shared information in order to end up with three leading practices namely: the partnership management of the supplier relationship, the exchange and the sharing of information and the management of the customer relationship. This is fundamentally explained by the fact that the quality of the shared information was not taken into account in the pilot study we conducted to test the questionnaire.

In terms of performance, we have taken into account both the financial and non-financial performance of the companies. It should be noted that section $\mathrm{C}$ of the questionnaire, focuses on the impact(s) of SCM practices on financial and non-financial performance, served as the basis for our analysis here. As a result, the perception of companies about their non-financial performance is measured by a single mediator variable. The answers are summarized in the tables and graphs below.

- Impact of the management of the supplier relationship on the financial and non-financial performance of the companies

Chart 1 describes the perception of companies about the impact of the management of the supplier relationship on their financial and non-financial performances.

It appears from the reading of graph one that only a proportion of $3.33 \%$ and $3.45 \%$ of the companies in our sample reflect that the management of the supplier relationship exerts a very small impact on the financial performance and not Financial.

Moreover, as indicated by the percentages of chart 1 , only a few firms believe that this practice has a low or medium impact on their financial and non-financial performance. However, more than half of the companies surveyed believe that the management of the supplier relationship has a high impact on their financial performance $(66.67 \%)$ and not financial $(62.07 \%)$. Those who find that this practice has a very high impact on their level of financial and non-financial performance represent only $6.67 \%$ and $6.9 \%$ respectively. 
Chart1: Impact du management de la relation fournisseur sur la performance des entreprises (\%)

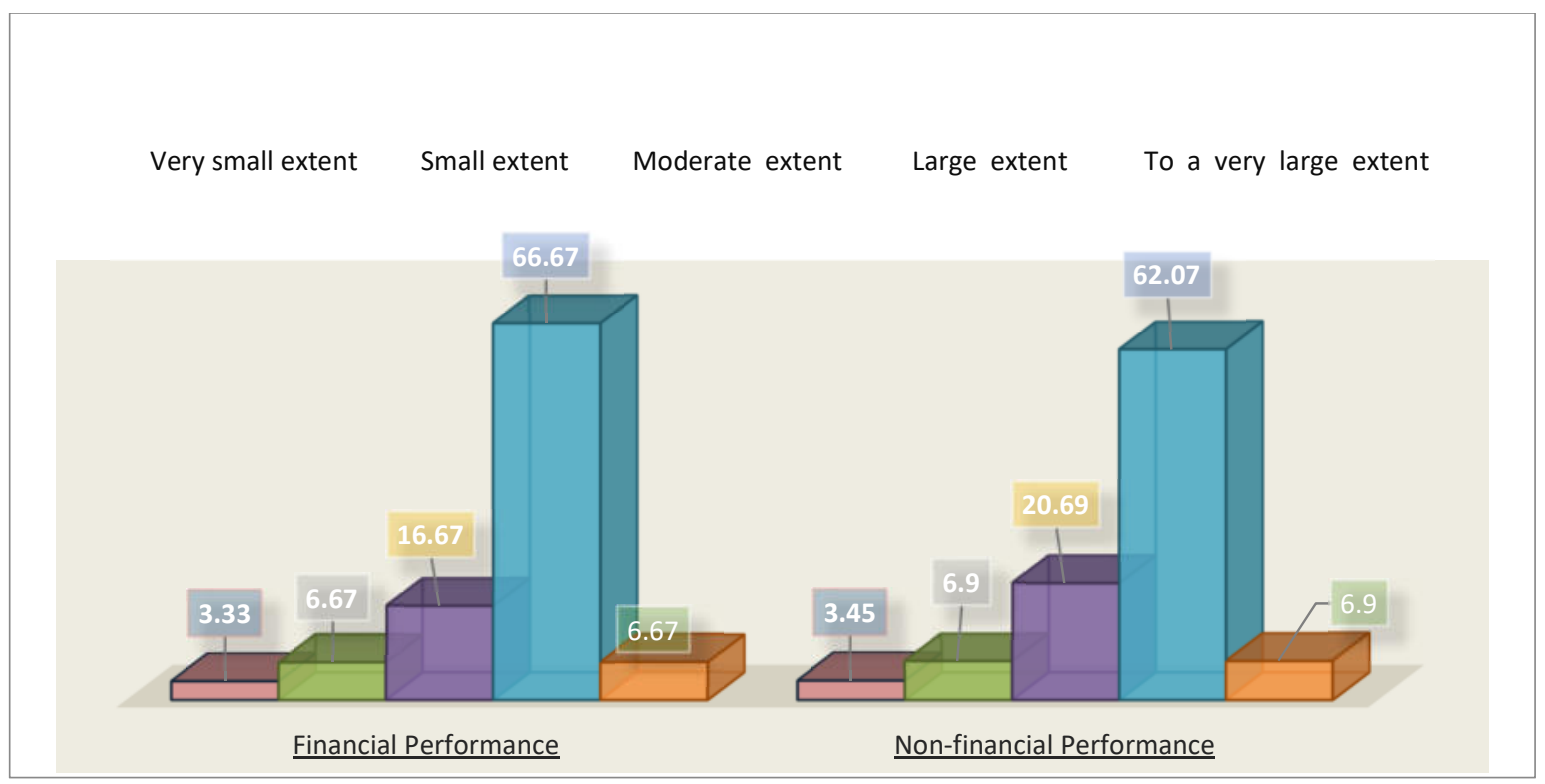

Source : Our calculations from our survey.

- Impact of the exchange and sharing of information on the financial and non-financial performance of companies.

Graph 2 provides information on the intensity of the impact of the exchange and the sharing of data on the financial and non-financial performance of companies.

The figures indicate that most companies, or $64.29 \%$, believe that exchange and sharing of information have a high impact on financial performance. However, only a proportion of $17.86 \%$ considers the impact to be very high. Chart 2 also shows that only 7.14\% of firms consider that exchange and sharing of information have a low impact on their financial performance, while $10.71 \%$ believe that this practice has a moderately low influence On financial performance.

At the same time, while the majority (53.57\%) of the companies surveyed indicated that the exchange and sharing of information exerted a high impact on their non-financial performance, about $14 \%$ considered the impact of this practice very high. On the other hand, less than $4 \%$ of the sample companies say that the exchange and sharing of information influently and very weakly affect their non-financial performance, while one-quarter of firms consider this practice to have a moderately low impact on their non-financial performance.

Chart 3 highlights the importance of the impact of the management of the customer relationship on the performance of the cotton sector companies. We find from the graph that no surveyed company finds that this practice influences very weakly its financial performance. On the other hand, $7.14 \%$ of them say that the management of the customer relationship has a low and moderately low impact on their financial performance. That being said, companies considering that this practice has a high and very high impact on their financial performance are more numerous. Each represents more than two thirds $(42.86 \%)$ of the sample.

Also, about $7 \%$ of companies believe that the impact of customer relationship management on non-financial performance is shallow and nearly $18 \%$ of them indicate that this practice has a moderately low impact on their level of performance. non-financial. However, half of the companies report that CRM has a high impact on their non-financial performance, while $25 \%$ find that the impact of this practice on non-financial performance is very high. 
Chart 2: Impact of the exchange and sharing of information on business performance (\%)

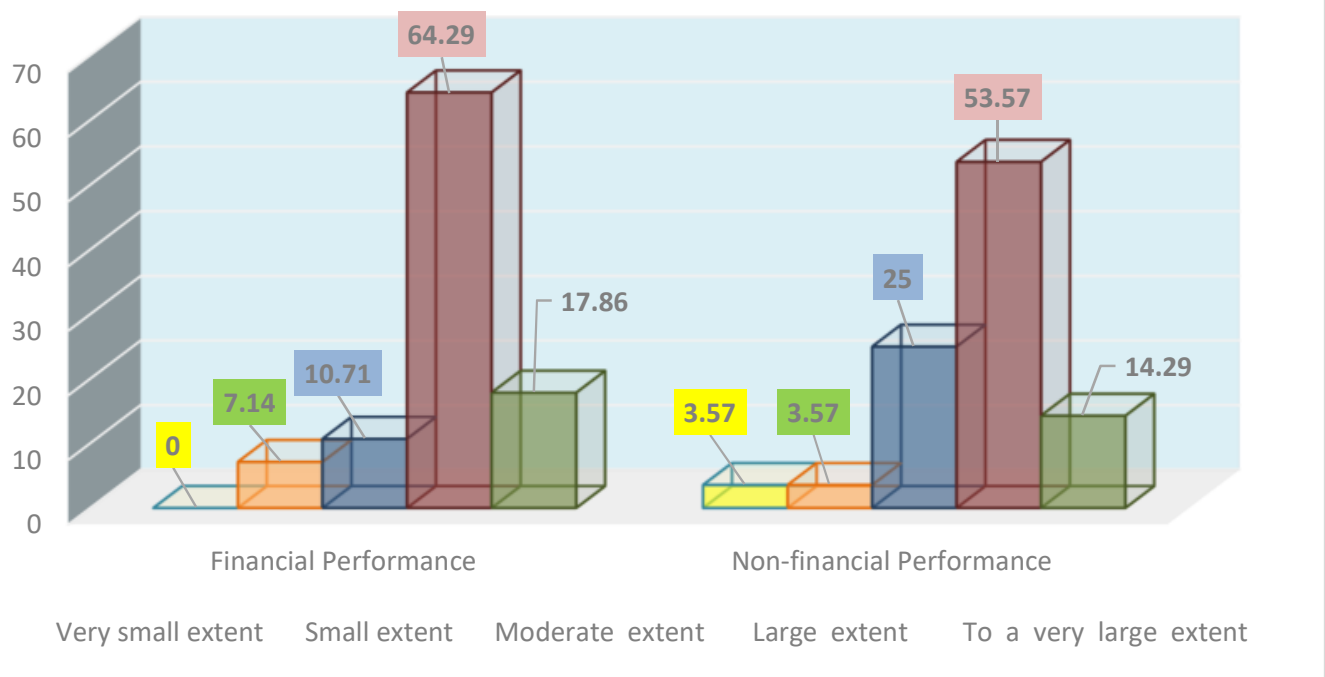

Source: Our calculations from our survey.

- Impact of the management of the customer relationship on the financial and non-financial performance of the companies.

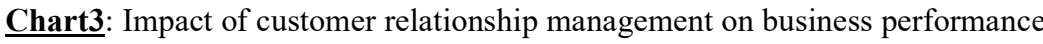

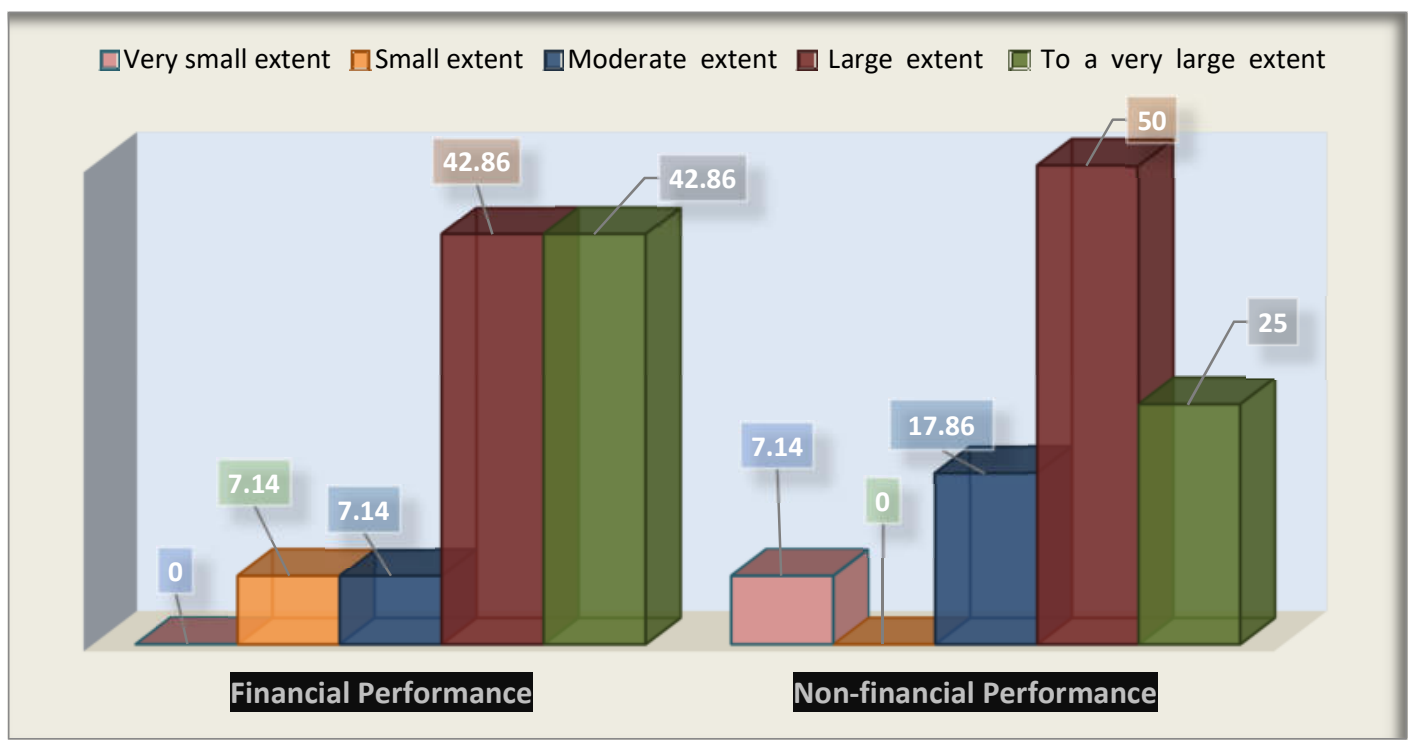

Source: Our calculations from our survey.

Overall, it appears from the data collected that most cotton companies reveal that the three practices considered in this study have a high impact on their financial and non-financial performances.

\subsection{The relationship between size, business practices and performance}

The objective of this part is to see how the relationship between the practices and the performance of the companies varies if one takes into account the size of the company. To simplify the analysis, we distinguished three categories of enterprises according to size: small businesses (those with fewer than 100 employees), medium-sized enterprises 
(those with a workforce between 100 and 500 employees) and Large companies (those with more than 500 employees). The results of this part are presented in the form of tables.

- Impact of the management of the supplier relationship on the financial and non-financial performance according to the size of the companies.

Tables 2 and three below describe the impact of the management of the supplier relationship on the financial and non-financial performance according to the size of the companies as well as for the whole sample.

A combined reading of the two tables reveals that only a share of $3.2 \%$ and $6.45 \%$ of companies agree that the management of the supplier relationship has no impact on financial and non-financial performance respectively.

An analysis according to size indicates that all small and large enterprises consider this practice to have an impact on their level of financial performance, unlike medium-sized enterprises, of which $4.76 \%$ of them say otherwise (Table 2).

Compared to table 3, we find that large companies admit, without exception, that the management of the supplier relationship has an impact on their non-financial performance. However, $14.29 \%$ and $4.76 \%$ of small and mediumsized enterprises say, respectively, that this practice does not influence their level of financial performance

Tableau 1: Impact of the management of the supplier relationship on the financial performance according to the size of the companies

\begin{tabular}{ccccc}
\hline & Small & Average & Great & Total \\
\hline Yes & 100 & 95,24 & 100 & 96,77 \\
& {$[7]$} & {$[20]$} & {$[3]$} & {$[30]$} \\
No & 0 & 4,76 & 0 & 3,23 \\
& {$[0]$} & {$[1]$} & {$[0]$} & {$[1]$} \\
Total & 100 & 100 & 100 & 100 \\
& {$[7]$} & {$[21]$} & {$[3]$} & {$[31]$} \\
& & & & \\
\hline
\end{tabular}

Source: Our calculations from our survey. Note: The table gives the percentages related to each modality. The digits [] refer to the number of observations.

Tableau 2: Impact of the management of the supplier relationship on the non-financial performance according to the size of the companies

\begin{tabular}{ccccc}
\hline & Small & Average & Great & Total \\
& & & & 100 \\
\hline \multirow{2}{*}{ Yes } & 85,71 & 95,24 & {$[3]$} & 93,55 \\
& {$[6]$} & {$[20]$} & 0 & $629]$ \\
& 14,29 & 4,76 & {$[0]$} & {$[2]$} \\
Total & {$[1]$} & {$[1]$} & 100 & 100 \\
& 100 & 100 & {$[3]$} & {$[31]$} \\
& {$[7]$} & {$[21]$} & & \\
\hline
\end{tabular}

Source : nos calculs à partir de notre enquête. Note: le tableau donne les pourcentages relatifs à chaque modalité. Les chiffres [] désignent le nombre d'observations.

- Impact of the exchange and sharing of information on financial and non-financial performances according to the size of the companies

Tables 4 and 5 present data on the impact of the exchange and the sharing of performance information by the size of the companies and the whole sample. 
It appears from the two tables that only about $10 \%$ of companies consider that the exchange and sharing of information do not affect their level of financial and non-financial performance.

A size analysis indicated that $28.57 \%$ of small businesses and $4.76 \%$ of medium-sized enterprises felt that this SCM practice did not affect the financial and non-financial performances of their businesses. These data differ from those of large companies, which in their entirety consider that the exchange and sharing of information influence both their financial and non-financial performances.

Table 3: Impact of the exchange and sharing of information on financial performance according to the size of the companies

\begin{tabular}{ccccc}
\hline & Small & Average & Great & Total \\
& & & & \\
\hline Yes & 71,43 & 95,24 & 100 & 90,32 \\
& {$[5]$} & {$[20]$} & {$[3]$} & {$[28]$} \\
No & 28,57 & 4,76 & 0 & 9,68 \\
& {$[2]$} & {$[1]$} & {$[0]$} & {$[3]$} \\
Total & 100 & 100 & 100 & 100 \\
& {$[7]$} & {$[21]$} & {$[3]$} & {$[31]$} \\
& & & & \\
\hline
\end{tabular}

Source: Our calculations from our survey. Note: The table gives the percentages related to each modality. The digits [] refer to the number of observations.

Tableau 4: Impact of the exchange and sharing of information on non-financial performance according to the size of the companies

\begin{tabular}{ccccc}
\hline & Small & Average & Great & Total \\
\hline Yes & 71,43 & 95,24 & 100 & 90,32 \\
& {$[5]$} & {$[20]$} & {$[3]$} & {$[28]$} \\
No & 28,57 & 4,76 & 0 & 9,68 \\
& {$[2]$} & {$[1]$} & {$[0]$} & {$[3]$} \\
Total & 100 & 100 & 100 & 100 \\
& {$[7]$} & {$[21]$} & {$[3]$} & {$[31]$}
\end{tabular}

Source: Our calculations from our survey. Note: The table gives the percentages related to each modality. The digits [] refer to the number of observations.

- Impact of the management of the customer relationship on the financial and non-financial performances according to the size of the companies

Tables 6 and 7 show the impact of the management of the customer relationship on the performance according to the size of the companies and the whole sample. It appears from the figures shown on both sides of the tables that among the companies surveyed, only about $10 \%$ of them found that the management of the customer relationship does not improve their financial and non-financial performances.

We also noted some differences in results depending on the size of the companies. Indeed, while $28.57 \%$ of small businesses and $4.76 \%$ of large companies say that this practice does not have an impact on their financial and nonfinancial performance, all large companies in the sample consider that the practice has an impact on Financial and non-financial performance. 
Table 5: Impact of the management of the customer relationship on the financial performance according to the size of the companies

\begin{tabular}{|c|c|c|c|c|}
\hline & Small & Average & Great & Total \\
\hline \multirow[t]{2}{*}{ Yes } & 71,43 & 95,24 & 100 & 90,32 \\
\hline & {$[5]$} & [20] & [3] & [28] \\
\hline \multirow[t]{2}{*}{ No } & 28,57 & 4,76 & 0 & 9,68 \\
\hline & {$[2]$} & [1] & [0] & [3] \\
\hline \multirow[t]{2}{*}{ Total } & 100 & 100 & 100 & 100 \\
\hline & [7] & [21] & [3] & [31] \\
\hline
\end{tabular}

Source: Our calculations from our survey. Note: The table gives the percentages related to each modality. The digits [] refer to the number of observations.

Table 6: Impact of customer relationship management on non-financial performance according to business size

\begin{tabular}{ccccc}
\hline & Small & Average & Great & Total \\
& & & & \\
\hline Yes & 71,43 & 95,24 & 100 & 90,32 \\
& {$[5]$} & {$[20]$} & {$[3]$} & {$[28]$} \\
No & 28,57 & 4,76 & 0 & 9,68 \\
& {$[2]$} & {$[1]$} & {$[0]$} & {$[3]$} \\
Total & 100 & 100 & 100 & 100 \\
& {$[7]$} & {$[21]$} & {$[3]$} & {$[31]$} \\
& & & & \\
\hline
\end{tabular}

Source: Our calculations from our survey. Note: The table gives the percentages related to each modality. The digits [] refer to the number of observations.

The evidence emerging from this section is that most sample companies consider the adoption of these three SCM practices to improve their level of financial and non-financial performance. However, there are still some disparities. An analysis of the size impact reveals that all large companies believe that these practices influence both their financial performance and their non-financial performance. While this is recognized by the majority of small and medium-sized enterprises, some of them say otherwise. Although the adoption of these three supply chain management practices plays an important role in the financial and non-financial performances of small and medium-sized enterprises, it appears through the answers provided that it benefits more the large companies in the cotton sector.

\subsection{The relationship between experience, business practices and performance}

In this section, I look at how the link between SCM practices and the performance of companies in the cotton sector following their years of experience. To carry out the analysis, we define two types of enterprises: companies with less experience in the cotton field (those with up to 10 years of activity in the sector) and companies with more experience in the sector (Those with more than 10 years of activity in the sector). The results are recorded in the various tables below.

- Impact of the management of the supplier relationship on the financial and non-financial performance according to the experience of the companies.

Tables 8 and 9 highlights the impact of the management of the supplier relationship on the performance of companies following their years of experience in the cotton sector and for the whole sample.

It appears from the two tables that all companies with low experience in the sector say that the management of the supplier relationship has an impact on their financial and non-financial performances.

However, the answers are different for companies with much experience in the industry. Indeed, about $7 \%$ and $14 \%$ of them believe that this practice does not influence their financial and non-financial performance respectively. 
Table 7: Impact of the management of the supplier relationship on the financial performance of the companies following their years of experience

\begin{tabular}{cccc}
\hline & Small & Great & Total \\
\hline Yes & 100 & 92,86 & 96,77 \\
& {$[17]$} & {$[13]$} & {$[30]$} \\
No & 0 & 7,14 & 3,23 \\
& {$[0]$} & {$[1]$} & {$[0]$} \\
Total & 100 & 100 & 100 \\
& {$[17]$} & {$[14]$} & {$[31]$}
\end{tabular}

Source: Our calculations from our survey. Note: The table gives the percentages related to each modality. The digits [] refer to the number of observations.

Table 8: Impact of the management of the supplier relationship on the non-financial performance of the companies following their years of experience

\begin{tabular}{cccc}
\hline & Small & Great & Total \\
\hline Yes & 100 & 85,71 & 93,55 \\
& {$[17]$} & {$[12]$} & {$[29]$} \\
No & 0 & 14,29 & 6,45 \\
& {$[0]$} & {$[2]$} & {$[2]$} \\
Total & 100 & 100 & 100 \\
& {$[17]$} & {$[14]$} & {$[31]$}
\end{tabular}

Source: Our calculations from our survey. Note: The table gives the percentages related to each modality. The digits [] refer to the number of observations.

- Impact of the management of the supplier relationship on the financial and non-financial performance following the experience of the companies

Tables 10 and 11 provide information on the impact of exchange and information sharing on business performance based on their years of experience.

It is clear from the two previous tables and that all companies with low cotton-related experience show that the exchange and sharing of information have an impact on their level of financial and non-financial performances. For companies with significant experience in the sector, $21.43 \%$ of them support the opposite result. 
Table 9: Impact of the exchange and sharing of information on the financial performance of companies following their years of experience

\begin{tabular}{cccc}
\hline & Small & Great & Total \\
\hline Yes & 100 & 78,57 & 90,32 \\
& {$[17]$} & {$[11]$} & {$[28]$} \\
No & 0 & 21,43 & 9,68 \\
& {$[0]$} & {$[3]$} & {$[3]$} \\
Total & 100 & 100 & 100 \\
& {$[17]$} & {$[14]$} & {$[31]$}
\end{tabular}

Source: Our calculations from our survey. Note: The table gives the percentages related to each modality. The digits [] refer to the number of observations.

Table 10: Impact of the exchange and sharing of information on the non-financial performance of companies following their years of experience

\begin{tabular}{cccc}
\hline & Small & Great & Total \\
\hline Yes & 100 & 78,57 & 90,32 \\
& {$[17]$} & {$[11]$} & {$[28]$} \\
No & 0 & 21,43 & 9,68 \\
& {$[0]$} & {$[3]$} & {$[3]$} \\
Total & 100 & {$[14]$} & 100
\end{tabular}

Source: Our calculations from our survey. Note: The table gives the percentages related to each modality. The digits [] refer to the number of observations.

- Impact of the management of the customer relationship on the financial and non-financial performances following the experience of the companies

Tables 12 and 13 show the impact of customer relationship management on performance following the number of years of business experience in the cotton sector.

The results obtained are similar to those in the previous tables. We also find that companies with a low experience consider that the management of the customer relationship has an impact on their financial and non-financial performance. Although this is not shared by all companies with extensive experience in the field of cotton, it appears from both tables that $78.57 \%$ of them confirm this point of view.

Table 11: Impact of the management of the customer relationship on the financial performance of the companies following their years of experience

\begin{tabular}{|c|c|c|c|}
\hline & Small & Great & Total \\
\hline \multirow[t]{2}{*}{ Yes } & 100 & 78,57 & 90,32 \\
\hline & [17] & {$[11]$} & {$[28]$} \\
\hline \multirow[t]{2}{*}{ No } & 0 & 21,43 & 9,68 \\
\hline & {$[0]$} & [3] & {$[3]$} \\
\hline \multirow[t]{2}{*}{ Total } & 100 & 100 & 100 \\
\hline & [17] & {$[14]$} & [31] \\
\hline
\end{tabular}

Source: Our calculations from our survey. Note: The table gives the percentages related to each modality. The digits [] refer to the number of observations. 
Table 12: Impact of the management of the customer relationship on the non-financial performance of the companies following their years of experience

\begin{tabular}{cccc}
\hline & Small & Great & Total \\
\hline Yes & 100 & 78,57 & 90,32 \\
& {$[17]$} & {$[11]$} & {$[28]$} \\
No & 0 & 21,43 & 9,68 \\
& {$[0]$} & {$[3]$} & {$[3]$} \\
Total & 100 & 100 & 100 \\
& {$[17]$} & {$[14]$} & {$[31]$} \\
& & & \\
\hline
\end{tabular}

Source: Our calculations from our survey. Note: The table gives the percentages related to each modality. The digits [] refer to the number of observations.

The analyses show that the supply chain management practices dealt with in this part would improve the performance of companies with low experience in the cotton sector; Those with greater experience value, in fact, less the importance of these practices in financial and non-financial performances. The impact of these three practices on performance seems to decrease as businesses evolve in the sector.

\section{Conclusion}

From the descriptive analysis, several results emerge. First, most of the companies in our sample reveal that the different SCM practices have a high impact on their financial and non-financial performance. Second, large companies believe that SCM practices influence both their financial performance and their non-financial performance.

On the other hand, some small and medium-sized enterprises say the opposite even if the majority recognize the favorable effect of SCM practices on their financial and non-financial performance. Third, SCM practices are more profitable for large companies. Fourth, supplier partnership, information exchange and sharing, and customer orientation would further enhance the performance of companies with limited experience in the cotton sector; On the other hand, those with more experience value the importance of these practices in financial and non-financial performance less.

At the end of this study, we must remember that the practices of the management of the supplier relationship and the exchange and sharing of information constitute the two best practices of the supply chain management of the performance for the companies of our sample. Also, among the dimensions of the performance considered, financial performance and customer satisfaction are the two most sensitive variants of SCM practices.

\section{Bibliographical references}

1. Balsmeier P.W., Voisin W. (1996), "Supply chain management: a time-based strategy", Industrial Management, Vol 38 N5, pp. 24-7.

2. Baulant C. (2007), « De l'Europe des nations à l'Europe des régions: intérêt de l'approche des clusters pour relancer la cooperation, Bilan et perspective d'un demi-siècle de construction de l'Union Européenne ", Warsow, University Press, pp. 170-185.

3. Brulhart F., Moncef B. (2010), «L'impact des pratiques de Supply Chain Management sur la performance de l'entreprise ", Finance Contrôle Stratégie, Vol 13, N¹, pp. 33-66.

4. Carr A.S., Person J.N. (1999), "Strategically managed buyers-seller relationships and performance outcomes”, Journal of Operations Management, Vol 17 N5, pp. 497-519.

5. Chen I.J., Paulraj A. (2004), "Towards a theory of supply chain management: the constructs and measurements”, Journal of Operation Management, Vol. 22, № 2, pp. 119-150.

6. Choi T.Y., Hartley J.L. (1996), “An exploration of supplier selection practices across the supply chain”, Journal of Operations Management, Vol. 14, N4, pp. 333-43. 
7. Claycomb C., Droge C., Germain R. (1999), "The effect of just-in-time with customers on organizational design and performance", International Journal of Logistics Management, Vol $10 \mathrm{~N}^{\circ} 1$, pp. 37-58.

8. Crook T.R, Combs J.G. (2007), "Sources and consequences of bargaining power in supply chains", Journal of Operations Management, Vol 25, pp. 546-555.

9. De Toni A., Nassimbeni G. (2000), "Just-in-time purchasing: an empirical study of operational practices, supplier development and performance", OMEGA, Vol 28, º6, pp. 631-51.

10. Deshpande R., Farley J.U., Webster F.E. (1993), “Corporate culture, customer orientation and innovativeness in Japanese firms: a quadrat analysis", Journal of Marketing, Vol. 57, January, pp. 23-37.

11. Hahn C.K., Pinto P.A., Brag D.J. (1983), "Just-in-time purchasing and the partnership strategy", European Journal of Purchasing and Supply Management (Fall) 2-10.

12. Jayaram J., Vickery S.K., Droge C. (1999). "An empirical study of time-based competition in the North American automotive supplier industry”, International Journal of Operations and Production Management, Vol. 19, №10, pp. 1010-1033

13. Kaplan R., Johnson T. (1987), Relevance Lost: The Rise and Fall of Management Accounting, Harvard Business School Press.

14. Simatupang T., Wright A. C., Sridharan R. (2002), "The knowledge of coordination for SC integration", Business Process Management Journal, Vol 8, º3, pp. 289-308.

15. Solakivi T. (2014), "The connection between supply chain practices and firm performance: evidence from multiple surveys and financial reporting data". Dissertation of thesis, Turku School of Economics, Series A-4: 2014.

16. Stanley L.L., Wisner J.D. (2001), "Service quality along the supply chain: implications for purchasing", Journal of Operations Management, Vol 19, º3, pp.287-306.

17. Stuart F.I. (1997), "Supply-chain strategy: organizational influence through supplier alliances ”, British Academy of Management, Vol. 8, N³, pp. 223-36.

18. Tan K.C., Lyman S.B., Wisner J.D (2002), "Supply chain management: a strategic perspective", International Journal of Operations and Production Management, Vol. 22, N6, pp. 614-31.

19. Tan K.C. (2001), "A framework of supply chain management literature”, European Journal of Purchasing and Supply Management, Vol. 7, $\mathrm{N}^{\circ} 1$, pp. 39-48.

20. Tan K.C., Kannan V.R. Handfield R.B. (1998)," Supply chain management, supplier performance and firm performance”, International Journal of Purchasing and Material Management, Vol. 34, N³, pp. 2-9.

21. Vickery S.K., Jarayam J., Droge C., Calantone R. (2003), "The effect of an integrative supply chain strategy on customer service and financial performance: an analysis of direct versus indirect relationships", Journal of Operations Management, Vol. 21, N5, pp. 523-539.

22. Yoshino M., Rangan S. (1995), "Strategic alliances: an entrepreneurial approach to globalization”, Boston, MA: Harvard Business School Press. 


\section{Annex}

Questionnaire: Determining the Impact of SCM Practices on Performance

To what extent do you agree with the following statement regarding the impact of chain management practices on your organization's financial performance? The scale below will be applicable: $1=$ very weak $2=$ weak $3=$ average $4=$ high $5=$ very high

\begin{tabular}{|c|c|c|c|c|c|}
\hline The practices of the management chain & 1 & 2 & 3 & 4 & 5 \\
\hline $\begin{array}{l}\text { Does the management of the supplier relationship } \\
\text { have an impact on financial performance? } \\
1 \text { yes } \\
\text { If so, how do you rate this impact? }\end{array}$ & & & & & \\
\hline $\begin{array}{l}\text { Does partnership management of the supplier } \\
\text { relationship have an impact on non-financial } \\
\text { performance? } \\
1 \text { yes } \\
\text { If no, how do you rate this impact? }\end{array}$ & & & & & \\
\hline $\begin{array}{l}\text { Does the exchange and sharing of information have } \\
\text { an impact on financial performance? } \\
1 \text { yes } \square \text { no } \\
\text { If so, how do you rate this impact? }\end{array}$ & & & & & \\
\hline $\begin{array}{l}\text { Does the exchange and sharing of information have } \\
\text { an impact on non-financial performance? } \\
1 \text { yes } \square \text { no } \\
\text { If so, how do you rate this impact? }\end{array}$ & & & & & \\
\hline $\begin{array}{l}\text { Does Customer Relationship Management Have an } \\
\text { Impact on Financial Performance? } \\
1 \text { oui } \square \text { non } \\
\text { If so, how do you rate this impact? }\end{array}$ & & & & & \\
\hline $\begin{array}{l}\text { Does Customer Relationship Management Have an } \\
\text { Impact on non- Financial Performance? } \\
1 \text { yes } \square 2 \text { no } \\
\text { If so, how do you rate this impact? }\end{array}$ & & & & & \\
\hline
\end{tabular}

